\title{
Structure, Morphology and Coarsening Behavior of MX (NbC) Nanoprecipitates in Fe-Ni-Cr Based Alloys
}

\author{
Milan Heczko ${ }^{1 *}$, Bryan D. Esser ${ }^{2}$, Roman Gröger ${ }^{1}$, Longsheng Feng ${ }^{2}$, Veronika Mazánová ${ }^{1}$, Yunzhi \\ Wang $^{2}$ and Michael J. Mills ${ }^{2}$ \\ ${ }^{1 .}$ CEITEC, Institute of Physics of Materials, Czech Academy of Sciences, Brno, Czech Republic \\ 2. The Ohio State University, Department of Materials Science and Engineering, Columbus, OH, USA \\ *Corresponding author: heczko@ipm.cz
}

The precipitates of MX-type (where $\mathrm{M}=\mathrm{Ti}, \mathrm{Nb}, \mathrm{V}, \mathrm{Mo}, \mathrm{Zr}, \ldots$ and $\mathrm{X}=\mathrm{C}, \mathrm{N}$ ) are considered as the most important strengthening phase in $\mathrm{Fe}-\mathrm{Ni}-\mathrm{Cr}$ based alloys designed for high temperature applications. Despite extensive effort focused on the study of this phase, many questions related to the structure, nucleation, coarsening behavior, as well as the mechanisms of interaction with dislocations, remain unanswered. This work is focused on Sanicro 25, a newly designed alloy with superior high temperature properties (e.g. the highest reported creep strength at $700^{\circ} \mathrm{C}$ among all commercial heatresistant austenitic steels) which are strongly determined by the precipitates of MX-type, in particular $\mathrm{NbC}$, nucleating during high temperatures [1]. Various thermo-mechanical experiments combined with state-of-the art electron microscopy and modelling tools were used to study structure, morphology, interface character and coarsening behavior of MX nanoprecipitates.

A set of specimens where the thermal exposure at $700^{\circ} \mathrm{C}$ was varied, combined without and with symmetrical cyclic tension-compression loading (see Figs. 1a and 1b), were cut and electron backscatter diffraction mapping was performed on polished cross-sections. Site- and orientation-specific thin foils were extracted using the focused ion beam. Regions with $\mathrm{NbC}$ precipitates were analyzed along different zone axis orientations using combined atomic-resolution high-angle annular dark-field (HAADF) scanning transmission electron microscopy (STEM) Z-contrast imaging, Super-X energydispersive X-ray spectroscopy, electron energy loss spectroscopy and nanobeam diffraction. NbC precipitates have a face-centered cubic crystal structure and are oriented in a cube-on-cube relationship with the austenite matrix (see Figs. 1c and 1d). They have a lattice parameter of $4.47 \AA$, i.e. a positive lattice misfit of about $24 \%$ relative to the matrix. Structural characteristics were further validated by HAADF-STEM image simulations of Moiré-like contrast using the quantum excitation of phonons model (Fig. 1e) [1, 2]. Several authors describe MX precipitates as coherent, semi-coherent or even incoherent; however, taking in account both lattice misfit and particle size, coherency with the matrix is very unlikely. Howe's [3] physical limit for misfit dislocation-based interfaces is at misfits of approximately $25 \%$ for which the spacing of misfit dislocations is close to $4 \boldsymbol{b}$ and their cores start to overlap. The large misfit measured for $\mathrm{NbC}$ in Sanicro 25 is very close to the Howe's limit. In the case of TiC, a variant of MX phase with lower lattice misfit than NbC, octahedra with $\{111\}$ facets and an interface consisting of a triangular network of misfit dislocations have been reported [4]. Our experimental data and structural characteristics were used as input in embedded atom model and phase field modelling to quantitatively confirm that the $\mathrm{NbC}$ precipitates indeed have the proposed shape and interface character with the matrix. Because of the large lattice misfit between the two crystal structures, precipitation of $\mathrm{NbC}$ in the defect-free matrix is extremely difficult. However, a large nucleation barrier can be overcome by nucleation at lattice defects, where part of the strain energy can be released by replacement of the dislocation line length and strain field with the precipitate nucleus. As the mode of 
$\mathrm{NbC}$ precipitation is profoundly affected by plastic deformation, the overall characteristics of nanoprecipitates in terms of their size and distribution can differ significantly depending on loading conditions. An example is shown in Figs. 1a and 1b. After exposure at $700^{\circ} \mathrm{C}$ for $153 \mathrm{~h}$, large particles of $50 \mathrm{~nm}$ in diameter are found nucleated only on dislocations. However, if cyclic loading (total strain amplitude $0.2 \%$ ) is also present during aging, arrays of much smaller $\mathrm{NbC}$ carbides approximately $8 \mathrm{~nm}$ in diameter are found heterogeneously dispersed with locally varying volume density. Our experimental data confirm that at the early stages of nucleation, it is possible for dislocations to break away from the $\mathrm{NbC}$, leaving behind a non-uniform distribution of nanoparticles. Moreover, once detached from dislocations, precipitates do not coarsen significantly. This conclusion is in agreement with Dutta et al. [5] who found that the coarsening mechanism of $\mathrm{Nb}(\mathrm{C}, \mathrm{N})$ is governed by accelerated pipe diffusion of $\mathrm{Nb}$ atoms along dislocation cores. If the dislocation on which the precipitate nucleates is detached under cyclic stress, accelerated pipe diffusion is no longer in operation and the precipitates do not grow significantly. The dispersoid-like arrangement of nanoscale $\mathrm{NbC}$ particles can be then maintained with further thermal exposure.

In summary, Sanicro 25 acts as a "smart" system at nanoscale as NbC precipitates are able to heterogeneously pin dislocations under high temperature fatigue loading, but once broken free of dislocations, they do not coarsen rapidly. Fundamental understanding of structure, morphology and coarsening behavior of MX precipitates for different thermo-mechanical treatment conditions will contribute to the design of new fine-precipitation strengthened materials [6].

\section{References:}

[1] M Heczko et al, Materials Science and Engineering A 719 (2018), p. 49.

[2] LJ Allen et al, Ultramicroscopy 151 (2015), p. 11.

[3] JM Howe in "Interfaces in Materials: Atomic Structure, Thermodynamics and Kinetics of SolidVapor, Solid-Liquid and Solid-Solid Interfaces”, (Wiley, New York) p. 544.

[4] N Cautaerts et al, Acta Materialia 164 (2019), p. 90.

[5] B Dutta, E Valdes and CM Sellars, Acta Metallurgica et Materialia 40 (1992), p. 653.

[6] The authors acknowledge support from the Thermo Fisher Scientific \& Czechoslovak Microscopy Society fellowship awarded to Milan Heczko.
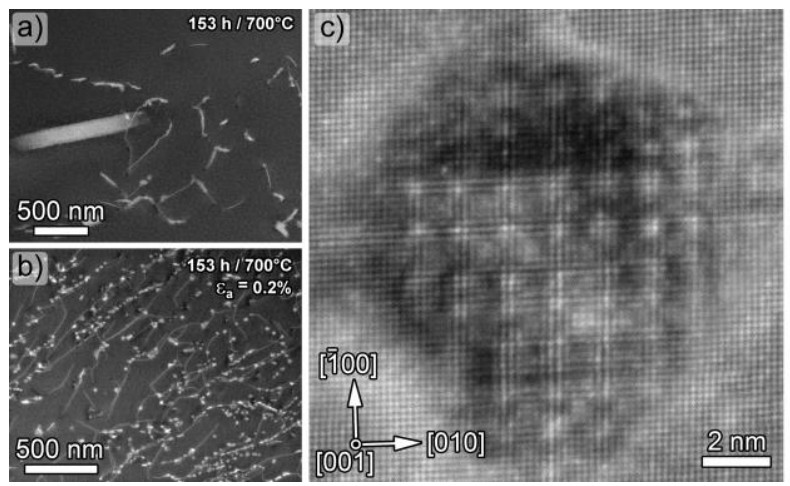

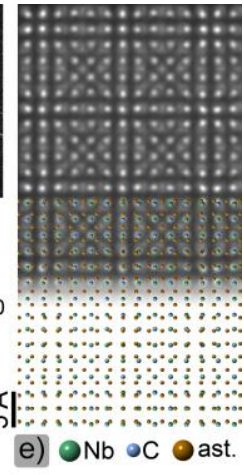

e) $\mathrm{Nb} \odot \mathrm{C} \odot$ ast.

Figure 1. HAADF-STEM image of Sanicro 25 alloy (a) aged only and (b) aged \& cyclically loaded with total strain amplitude of $0.2 \%$ at $700^{\circ} \mathrm{C}$ for $153 \mathrm{~h}$. (c) $\mathrm{NbC}$ precipitate overlapping with matrix and forming Moiré-like contrast in HAADF-STEM [001] zone axis imaging. (d) FFT pattern \& schematic corresponding to image (c). (e) Simulated Moiré-like contrast. HAADF-STEM image simulated along [001] zone axis is compared with structural model of overlapping $\mathrm{NbC}$ and austenitic matrix. 